\title{
Structural and thermodynamic studies of the tobacco calmodulin-like rgs-CaM protein
}

\author{
Rodrigo K. Makiyama ${ }^{\mathrm{a}, 1}$, Carlos A.H. Fernandes ${ }^{\mathrm{b}, 1}$, Thiago R. Dreyer ${ }^{\mathrm{b}}$, Bruno S. Moda ${ }^{\mathrm{a}}$, \\ Fabio F. Matioli ${ }^{\mathrm{b}}$, Marcos R.M. Fontes ${ }^{\mathrm{b}}$, Ivan G. Maia ${ }^{\mathrm{a}, *}$ \\ a Universidade Estadual Paulista (UNESP), Instituto de Biociências, Departamento de Genética, Botucatu, SP, Brazil \\ b Universidade Estadual Paulista (UNESP), Instituto de Biociências, Departamento de Física e Biofísica, Botucatu, SP, Brazil
}

\section{A R T I C L E I N F O}

\section{Article history:}

Received 25 January 2016

Received in revised form 8 July 2016

Accepted 7 August 2016

Available online 8 August 2016

\section{Keywords:}

$\mathrm{Ca}^{2+}$-binding protein

Calmodulin-like protein

rgs-CaM

\begin{abstract}
A B S T R A C T
The tobacco calmodulin-like protein rgs-CaM is involved in host defense against virus and is reported to possess an associated RNA silencing suppressor activity. Rgs-CaM is also believed to act as an antiviral factor by interacting and targeting viral silencing suppressors for autophagic degradation. Despite these functional data, calcium interplay in the modulation of rgs-CaM is still poorly understood. Here we show that rgs-CaM displays a prevalent alpha-helical conformation and possesses three functional $\mathrm{Ca}^{2+}$-binding sites. Using computational modeling and molecular dynamics simulation, we demonstrate that $\mathrm{Ca}^{2+}$ binding to rgs-CaM triggers expansion of its tertiary structure with reorientation of alpha-helices within the EF-hands. This conformational change leads to the exposure of a large negatively charged region that may be implicated in the electrostatic interactions between rgs-CaM and viral suppressors. Moreover, the $\mathrm{k}_{d}$ values obtained for $\mathrm{Ca}^{2+}$ binding to the three functional sites are not within the affinity range of a typical $\mathrm{Ca}^{2+}$ sensor.
\end{abstract}

(c) 2016 Elsevier B.V. All rights reserved.

\section{Introduction}

RNA silencing is a potent host defense mechanism against plant viruses that is counteracted by viral proteins possessing RNA silencing suppression activities [1]. Host proteins acting as suppressors of RNA silencing have also been identified and a Nicotiana tabacum calmodulin-like protein called rgs-CaM (for regulator of gene silencing camodulin-like) was the first whose suppression activity was demonstrated [2]. The tobacco rgs-CaM was shown to interact with the helper-component proteinase (HC-Pro), a viral RNA silencing suppressor, and was postulated to be required for HCPro-mediated silencing suppression. Consistent with this, Li et al. [3] demonstrated that an rgs-CaM homolog of $N$. benthamiana is required for the RNA silencing suppression activity of $\beta C 1$, a suppressor encoded by the satellite DNA of Tomato yellow leaf curl China virus. Contradictory findings, however, have shown that the interaction of rgs-CaM with different viral suppressors has an antiviral function [4]. In this case, rgs-CaM is supposed to counteract viral suppressors by binding to their double-stranded RNA (dsRNA)-

\footnotetext{
* Corresponding author.

E-mail addresses: igmaia@ibb.unesp.br, igmaia1@gmail.com (I.G. Maia).

1 These authors contributed equally to this work
}

binding domains and targeting them for autophagic degradation. Moreover, the proposed mechanism requires self-sacrifice of the rgs-CaM protein. Evolving knowledge indicates that rgs-CaM is an early-inducible gene implicated in the initial steps of viral infection [5].

Despite sharing similarity with calmodulins (CaM) and Calmodulin-like proteins (CML), little is known about the structural features of rgs-CaM. Such structural studies are important to shed light on the function of rgs-CaM and also to elucidate its interaction with target viral suppressors. As mentioned above, rgs-CaM was shown to interact with viral suppressors via their positively charged dsRNA-binding domains [4]. This interaction was reported to be mediated by electrostatic interactions [4], a distinctive feature compared to classical CaMs that usually bind to their target proteins through hydrophobic interactions [6,7]. In this regard, the crucial roles of electrostatic interactions in the cooperativity of calcium binding and in protein aggregation have been highlighted by several studies [8-11].

This peculiar characteristic of rgs-CaM in comparison to other CaMs suggests that rgs-CaM may exhibit unique structural proprieties. In addition, as highlighted by Tadamura et al. [5], rgs-CaM is the only known CML protein able to bind to exogenous targets. In contrast, classical CaMs interact with endogenous targets using canonical helix-loop-helix EF-hand motifs for $\mathrm{Ca}^{2+}$ binding [12]. 
These EF-hands frequently occur in pairs and most CaMs possess two, four or six EF-hands [12].

The structure of CaMs is generally well conserved and presents $\mathrm{N}$ - and C-terminal globular lobes linked by a central alpha helix [13]. Each lobe possesses two EF-hand motifs containing a $\mathrm{Ca}^{2+}$ binding loop composed of a cluster of 12 amino acid residues that usually starts with an Asp and ends with a Glu. Residues essential for $\mathrm{Ca}^{2+}$ binding coordination within this cluster are in positions 1 , $3,5,7,9$ and 12 , respectively $[12,14]$.

In this study, we examined the $\mathrm{Ca}^{2+}$ binding properties of rgsCaM in order to learn more about its functionality. For this, the tobacco rgs-CaM was expressed in Escherichia coli and purified. Subsequently, the binding affinities and possible conformational changes associated with $\mathrm{Ca}^{2+}$ binding to recombinant rgs-CaM were investigated using different biophysical and computational approaches (circular dichroism, isothermal titration calorimetry, molecular modeling and molecular dynamics simulations).

\section{Materials and methods}

\subsection{Construction of the rgs-CaM expression vector}

The cDNA encompassing the open reading frame of tobacco rgs-CaM (accession number AF329729) was amplified by RT-PCR using total RNA extracted from leaves of $N$. tabacum SR1 and gene-specific primers supplemented with the restriction sites for NdeI and Xhol (5'-GGCCATATGTGCATGGAATCAGTTTC-3' and 5'-CTACTCGAGACTTGTCATCATAGCTTTGAAC-3'; sites underlined). The amplified fragment was gel-purified and cloned into the NdeI- and Xhol-digested expression vector pET-28a (Novagen). The resulting construct was sequenced and subsequently inserted into E. coli BL21(DE3)-CodonPlus-pRIL cells (Stratagene) for expression.

\subsection{Expression and purification of recombinant his-tagged rgs-CaM}

Transformed E. coli cells were grown overnight at $37^{\circ} \mathrm{C}$ in Luria-Bertani medium supplemented with $100 \mathrm{mg} / \mathrm{l}$ kanamicin and $50 \mathrm{mg} / \mathrm{l}$ chloramphenicol. The culture was diluted $(1: 100)$ in the same medium and grown at $37^{\circ} \mathrm{C}$ to an $\mathrm{OD}_{600}$ of 0.7 , followed by addition of $1 \mathrm{mM}$ isopropyl- $\beta$-D-thiogalactopyranoside (IPTG) and induction for $4 \mathrm{~h}$ at $28^{\circ} \mathrm{C}$. The harvested cells were resuspended in lysis buffer ( $50 \mathrm{mM}$ Tris- $\mathrm{HCl}, \mathrm{pH} 7.5,50 \mathrm{mM} \mathrm{NaCl}, 0.25 \%$ Tween 20, $1 \mathrm{mM}$ EDTA and $1 \mathrm{mM}$ PMSF) supplemented with lysozyme $(1 \mathrm{mg} / \mathrm{ml})$, RNAse A $(1 \mu \mathrm{g} / \mathrm{ml})$ and DNAse I $(10 \mathrm{u} / \mathrm{ml})$. After breaking the genomic DNA by sonication $(6 \times 30 \mathrm{~s})$, the suspension was centrifuged $\left(20.000 \times g\right.$ for $30 \mathrm{~min}$ at $\left.4{ }^{\circ} \mathrm{C}\right)$. The pellets of inclusion bodies were washed twice in buffer A ( $50 \mathrm{mM}$ Tris-HCl, $\mathrm{pH} \mathrm{8.0,} \mathrm{and}$ $100 \mathrm{mM} \mathrm{NaCl}$ ), and solubilized $\left(30\right.$ min at $4^{\circ} \mathrm{C}$ ) by addition of buffer A containing $1 \%$ sodium dodecyl sulfate (SDS). The recombinant protein was then refolded in the presence of $2 \mathrm{M}$ 2-methyl-2,4pentanediol (MPD) $[15,16]$. For this, the samples were incubated at $4{ }^{\circ} \mathrm{C}$ for $24 \mathrm{~h}$ under gentle agitation. Subsequent purification of recombinant His-tagged rgs-CaM (rgs-CaM:His) was performed by affinity chromatography using Ni-NTA columns pre-equilibrated with buffer A (plus 1\% SDS and 2 M MPD) as recommended by the manufacturer (Qiagen), followed by size exclusion chromatography using Superdex 75 10/300 GL columns (GE Healthcare) that were equilibrated with buffer A containing $2 \mathrm{M}$ MPD. All columns were linked to a high-performance liquid chromatography system (AKTA Purifier 900; GE Healthcare) and a flow rate of $0.5 \mathrm{ml} / \mathrm{min}$ was used. Fractions containing recombinant rgs-CaM:His were checked by standard SDS-PAGE ( $0.1 \%$ SDS, $12 \%$ polyacrylamide), stained with Coomassie blue, and also by western blot using a monoclonal anti-polyHistidine antibody (Sigma) and the ECL Western Blot- ting Analysis System as recommended by the manufacturer (GE Healthcare). Protein concentration was determined by absorbance at $280 \mathrm{~nm}$ in a NanoDrop 2000C spectrophotometer (Thermo Scientific), using theoretical molecular weights and extinction coefficients provided by the in silico ProtParam tool available on the ExPASy web server (http://web.expasy.org/protparam) [17].

\subsection{Semi-denaturing mobility-shift assays}

The semi-denaturing mobility-shift assay was performed essentially as described [18] using $3 \mu \mathrm{g}$ of recombinant rgs-CaM in buffer A (containing $2 \mathrm{M}$ MPD) supplemented with either $5 \mathrm{mM} \mathrm{CaCl}_{2}$ or $5 \mathrm{mM}$ ethylene glycol bis(beta-aminoethyl ether)-N,N'-tetraacetic acid (EGTA). The samples were incubated at $4{ }^{\circ} \mathrm{C}$ for $30 \mathrm{~min}$ and suspended without boiling in sample buffer $(62.5 \mathrm{mM}$ Tris- $\mathrm{HCl}, \mathrm{pH} 6.8$, $1 \%$ SDS, $10 \%$ glycerol) devoid of $\beta$-mercaptoethanol. Each protein sample was subsequently electrophoresed on a precast $16 \%$ polyacrylamide gel containing no SDS (ECL Precast Gel; GE Healthcare). The gel was stained with Coomassie blue.

\subsection{Circular dichroism (CD) spectroscopy}

$\mathrm{CD}$ measurements were obtained over the spectral range of 200-260 nm using a JASCO J-815 spectropolarimeter (JASCO Spectroscopic Co. Ltd., Japan) equipped with a Peltier thermo-controller. The assays were carried out at $293 \mathrm{~K}$ using an optical path length of $0.5 \mathrm{~nm}$, a scanning speed of $100 \mathrm{~nm} / \mathrm{min}$, response time of $1 \mathrm{~s}$, band width of $2 \mathrm{~nm}$ and data pitch of $0.5 \mathrm{~nm}$. Twenty spectra were acquired, averaged and corrected for the buffer solution (baseline) and then normalized to residual molar ellipticity [ $\theta]$. Previously to CD measurements, rgs-CaM was treated with excess of EGTA to remove possible residual $\mathrm{Ca}^{2+}$ bound to its structure, and the solution was subsequently dialyzed against buffer A (containing $2 \mathrm{M}$ MPD). The effect of $\mathrm{Ca}^{2+}$ in $\mathrm{CD}$ spectra was also evaluated by the addition of $5 \mathrm{mM} \mathrm{CaCl}_{2}$ to the protein sample, in the absence or presence of $5 \mathrm{mM}$ EGTA. Buffer A plus MPD, $\mathrm{CaCl}_{2}$ and EGTA gave negligible signals at the concentrations tested and were included in baseline measurements.

\subsection{Isothermal titration calorimetry (ITC)}

The thermodynamic parameters of the interaction between rgs$\mathrm{CaM}$ and calcium ions were determined at $25^{\circ} \mathrm{C}$ in buffer $\mathrm{A}$, using an isothermal titration calorimeter (MicroCal ITC 200 , GE Healthcare). Prior to the ITC assays, rgs-CaM was treated with excess EGTA to remove possible residual $\mathrm{Ca}^{2+}$ bound to its structure, and the solution was subsequently dialyzed against the buffer used in the titration to remove EGTA from the final solution. For a typical $\mathrm{Ca}^{2+}$ titration, $0.2 \mathrm{mM}$ of recombinant rgs-CaM was placed in the reaction cell $(200 \mu \mathrm{l})$ and a $10 \mathrm{mM} \mathrm{Ca}^{2+}$ solution was loaded into the ITC syringe. Each $2.5 \mathrm{~min}, 2 \mu \mathrm{l}$ of $\mathrm{Ca}^{2+}$ solution was injected into the reaction cell. $\mathrm{Ca}^{2+}$ heat of dilution/mixing were determined in separate control assays and were subtracted from the corresponding titrations. For the stoichiometry $(N)$, dissociation constants $\left(K_{\mathrm{d}}\right)$, enthalpy $(\Delta H)$, and binding-type input parameters were adjusted to obtain the best fitting model. The values of $K_{\mathrm{d}}$ and $\Delta H$ were used to calculate the change in free energy $(\Delta G)$ and entropy $(\Delta S)$ of $\mathrm{Ca}^{2+}$ binding.

\subsection{Modeling and molecular dynamics (MD) simulations}

According to the data obtained from the based-threading method program HHPred (http://toolkit.tuebingen.mpg.de/ hhpred) [19] (score: 169.12; e-value: 2.1e-32; identity: 33\%), the crystal structure at $1.0 \AA$ resolution of a CaM from Paramecium tetraurelia [Protein Data Bank (PDB) ID: 1EXR] was selected as 
the best template for initial in silico rgs-CaM structural modeling. Besides, the crystallographic structures of CaMs from Saccharomyces cerevisae, Physarum polycephalum, Entamoeba histolytica, Kluyveromyces lactis, Chalamydonas reinhardtii and Homo sapiens (PDB IDs, respectively, 3FWD, 2B10, 40CI, 4DS7, 3QRX and 2OBH) were also identified as putative templates. However, their crystal structures presented lower resolution values and shared limited sequence identity with the rgs-CaM primary sequence (lower than $28 \%$ ).

The initial in silico model of the rgs-CaM structure was generated using the program MODELLER v.9.10 [20]. Since the first $47 \mathrm{~N}$-terminal residues of rgs-CaM possess no homology with any CaM structure deposited in PDB, they were not included in the model. Calcium ions were modeled at the four putative $\mathrm{Ca}^{2+}$ binding loops of the rgs-CaM structure and the generated model (called rgs-CaM + Ca-A-B-C-D) was submitted to MD simulations using the program package GROMACS (Groningen Machine for Chemical Simulation) v.4.5.3 [21] in the presence of explicit water molecules. Protonation states of charged groups were set according to $\mathrm{pH}$ 7.0. Counter ions were added to neutralize the system and the GROMOS 96 53a6 force field [22] was chosen to perform the MD simulations. The minimum distance between any atom of the protein and the box wall was $1.0 \mathrm{~nm}$.

In the next step, four additional models were generated removing one (rgs-CaM-Ca-A-B-D model), two (rgs-CaM+Ca-A-D), three (rgs-CaM+Ca-C) and four (apo-rgs-CaM) calcium ions from the four putative $\mathrm{Ca}^{2+}$-binding loops as found in the CaM of $P$. tetraurelia used as model. The letters A, B, C and D denote the presence of calcium in the corresponding $\mathrm{Ca}^{2+}$-binding loops. For all models, energy minimization (EM) using steepest descent algorithm was performed to generate the starting configuration of the system. After this step, $200 \mathrm{ps}$ of MD simulation with position restraints applied to the protein (PRMD) was executed to gently relax the system. All the MD simulations were carried out in a periodic truncated dodecahedron box under constant temperature $(298 \mathrm{~K})$ and pressure (1.0 bar) maintained by the coupling to an external heat and an isotropic. Then, $200 \mathrm{~ns}$ for the rgs-CaM+Ca-A-B-D model and $100 \mathrm{~ns}$ for the remaining models of unrestrained MD simulations were calculated to evaluate the stability of all the structures generated. The overall quality of all in silico models obtained after MD simulation was checked using RAMPAGE [23] and ProSA-web (https://prosa. services.came.sbg.ac.at/prosa.php). The average root mean square fluctuations (RMSF) of the backbone atoms from the final models were calculated and converted to B-factor values using GROMACS v.4.5.3 [21] (Suppl. Fig. 1). The same program was used to calculate the radius of gyration $(\mathrm{Rg})$ of each model during MD simulation. The electrostatic potential surfaces of the in silico models were generated by APBS (Adaptive Poisson-Boltzmann Solver) electrostatic calculations at $150 \mathrm{mM} \mathrm{NaCl}$ with a probe size of $1.4 \AA$ on Chimera v.1.9 [24], after the conversion of the PDB file into a PQR file $(\mathrm{pH}$ 7.0) using the online server PDB2PQR with the PARSE force field [25]. All structural figures were generated using Chimera v.19 [24] and PyMOL v.1.3 [26].

\section{Results}

\subsection{Expression and purification of soluble rgs-CaM}

Expression of the His-tagged rgs-CaM in E. coli resulted in a polypeptide with an apparent molecular mass of $21 \mathrm{kDa}$ (Fig. 1A), which was present in the insoluble inclusion body fraction (Fig. 1B). After several unsuccessful attempts of solubilization in nondenaturing conditions, the inclusion bodies were solubilized using SDS and the recombinant protein was refolded in the presence of the amphipathic solvent MPD. MPD has been successfully used in the refolding of SDS-denatured proteins avoiding disruption of the protein structure $[15,16]$. After refolding, the recombinant rgsCaM was further purified using a combination of metal affinity chromatography on a Ni-NTA column and size exclusion chromatography (Fig. 1C). Purification resulted in a single band of $22 \mathrm{kDa}$, visible on SDS-PAGE, which is close to the estimated molecular mass of native rgs-CaM ( $21 \mathrm{kDa})$. Purified rgs-CaM was further recognized by a His-tag monoclonal antibody in western blot analysis, thus confirming correct fusion. It should be noted that the His-tag was not removed from purified rgs-CaM for subsequent analyses.

\subsection{Secondary structural predictions using CD spectroscopy}

The structural integrity of the refolded rgs-CaM was checked using CD spectroscopy. The resulting CD spectrum displayed minimum values around 208 and $222 \mathrm{~nm}$, indicating a structured conformation (Fig. 2A). These two minima are typically observed in proteins with significant alpha-helical content, which is the case of plant CaMs [27]. To characterize a possible conformational change of rgs-CaM upon $\mathrm{Ca}^{2+}$ binding, $\mathrm{CD}$ spectra were further recorded in the presence of $5 \mathrm{mM} \mathrm{CaCl}$ and after the addition of $5 \mathrm{mM}$ EGTA. As shown in Fig. 2B, the addition of $\mathrm{Ca}^{2+}$ to rgs-CaM promoted a slight increase in molar ellipticity at $222 \mathrm{~nm}$. In contrast, no spectral changes were detected in the presence of EGTA as compared to purified rgs-CaM (apo-rgs-CaM). A modest effect on the CD spectrum after $\mathrm{Ca}^{2+}$ addition was also observed for two CMLs from Arabidopsis thaliana (designated CML42 and CML43) [28,29]. However, for both proteins, the observed effect was attributed to a helix reorientation rather than to an increase in alpha helix content after $\mathrm{Ca}^{2+}$ binding $[28,29]$.

\subsection{Calcium promotes a shift in rgs-CaM mobility}

Calcium ions have been reported to alter the electrophoretic mobility of $\mathrm{Ca}^{2+}$-binding proteins by promoting faster migration compared to proteins maintained in a $\mathrm{Ca}^{2+}$-free state [30,31]. We therefore tested the effect of $\mathrm{Ca}^{2+}$ on the migration of recombinant rgs-CaM using a semi-denaturing mobility-shift assay. When $\mathrm{CaCl}_{2}$ was added to rgs-CaM just before electrophoresis, a faster migration of $\mathrm{CaCl}_{2}$-treated rgs-CaM as compared to purified rgs-CaM was noted (Fig. 3). In contrast, no shift was observed when EGTA was added to the protein sample containing $5 \mathrm{mM} \mathrm{CaCl}_{2}$. In this case, the EGTA-treated rgs-CaM migrated similarly to purified rgs-CaM.

\subsection{ITC results indicate the presence of three $\mathrm{Ca}^{2+}$-binding sites in rgs-CaM}

A typical set of ITC data for $\mathrm{Ca}^{2+}$ interaction with rgs-CaM is shown in Fig. 4. Higher and lower panels show the raw calorimetric data for the $\mathrm{Ca}^{2+}$-into-rgs-CaM titration and the binding isotherm, respectively. Based on primary sequence analyses (Fig. 5), a sequential four-binding site model was used to fit ITC data as previously described $[29,32,33]$. In this regard, the resulting calorimetry data was best fitted by the three $\mathrm{Ca}^{2+}$-binding site model (Table 1 and Fig. 4), which presented the lower chi-square value (128.8) compared to the two- and four-binding site models (162.0 and 198.8, respectively). This is in line with a previous assumption suggesting the existence of only three $\mathrm{Ca}^{2+}$-binding sites in rgs-CaM [2]. It should also be emphasized that the interaction of rgs-CaM with $\mathrm{Ca}^{2+}$ displayed a negative enthalpy change, indicative of an exothermic binding event (Table 1 ). 
A)

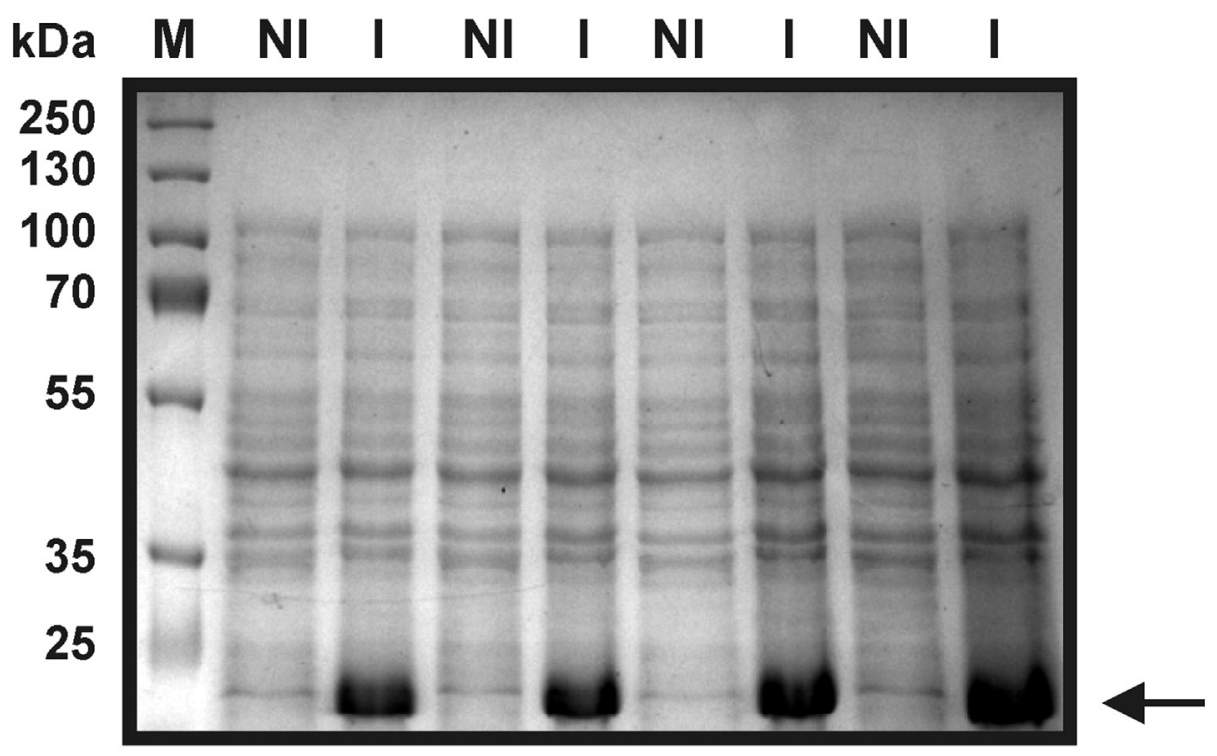

B)

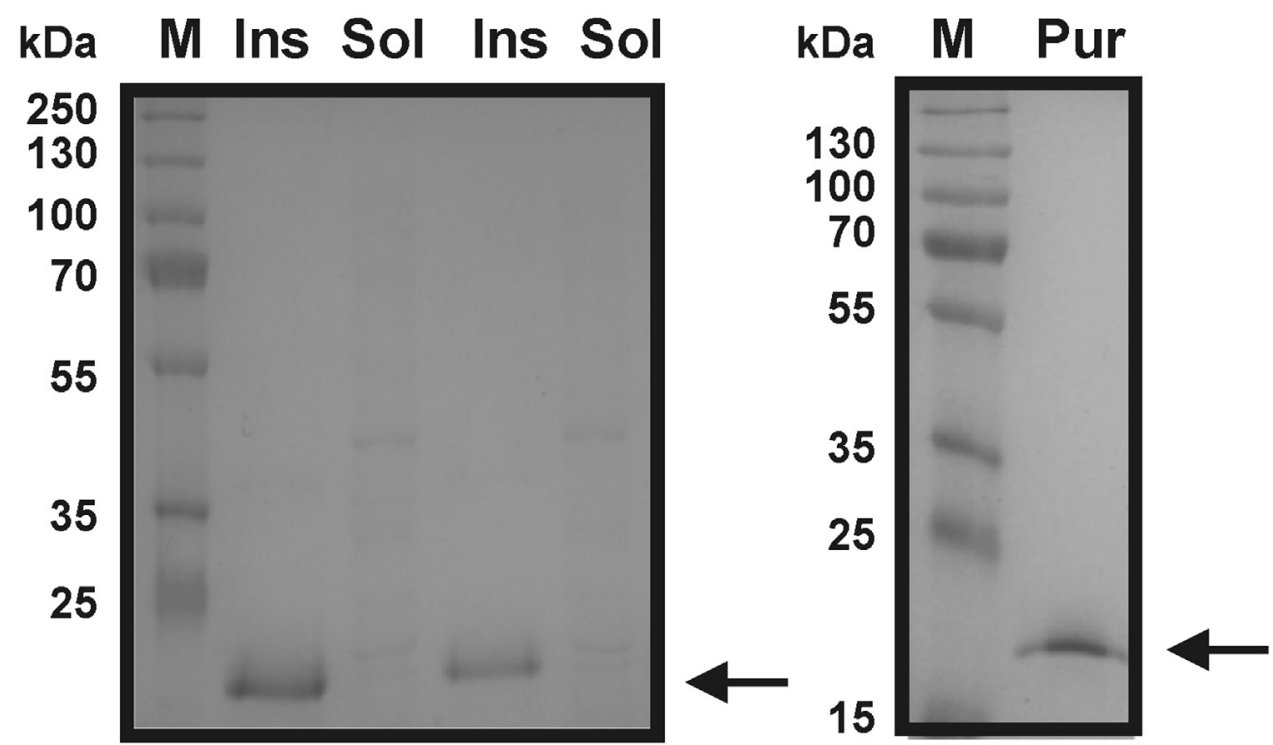

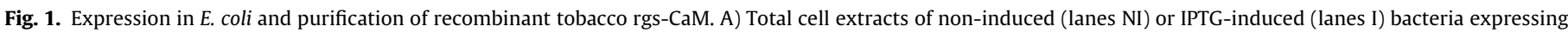

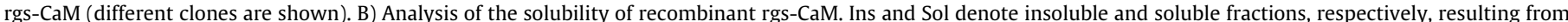

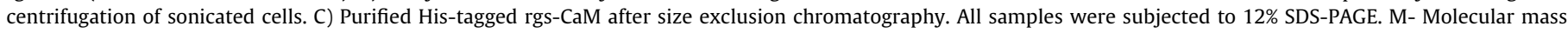
standard in kDa (PageRuler Plus Ladder 10-250 kDa; Fermentas). Gels were stained with Coomassie Brilliant Blue.

\subsection{Primary sequence comparisons and homology modeling} highlights the presence of three $\mathrm{Ca}^{2+}$-binding sites in rgs-CaM

A search for proteins structurally related to rgs-CaM using the HHpred server revealed structural similarity to CaMs from $K$. lactis (PDB ID: 4DS7), P. tetraurelia (PDB ID: 1EXR) and H. sapiens (PDB ID: 30X6). Inspection of the primary structure alignment (Fig. 5A) revealed that only three out of the four putative $\mathrm{Ca}^{2+}$-binding loops of rgs-CaM (indicated as A, B and D) have a canonical 12-residue $\mathrm{Ca}^{2+}$-binding loop sequence signature [D-X-Y-X-Y-G-X- $\Psi-\mathrm{X}-\mathrm{X}-\mathrm{X}-$ $\mathrm{E}$, where $\mathrm{Y}$ indicates either $\mathrm{D}$ or $\mathrm{N}$ residues, and $\Psi$ indicates a hydrophobic residue] [12]. On the other hand, loop $C$ showed no conservation of $\mathrm{D} / \mathrm{N}$ residues at positions 1,3 and 5 , and of $\mathrm{E}$ at position 12, therefore suggesting possible non-functionality (Fig. 5A). Further comparative information about these loops is provided by the alignment (Fig. 5B) of rgs-CaM with CML42 and CML43 from $A$. thaliana that also possess only three $\mathrm{Ca}^{2+}$-binding sites [28,29].

To obtain further structural insights into the $\mathrm{Ca}^{2+}$ coordination of rgs-CaM, we generated in silico models for apo-rgs-CaM and for rgs-CaM loaded with four (rgs-CaM+Ca-A-B-C-D), three (rgs-CaM+Ca-A-B-D model), two (rgs-CaM+Ca-A-D model) and one (rgs-CaM+Ca-C model) $\mathrm{Ca}^{2+}$ ions (Table 2; Fig. $6 \mathrm{~A}$ and $\mathrm{B}$ ). The in sil- 


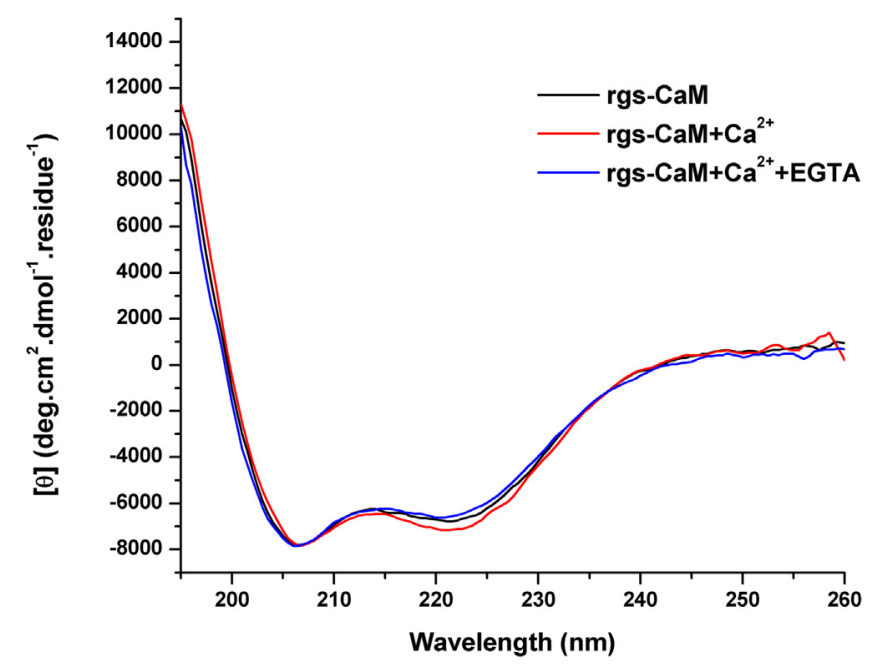

Fig. 2. Far-UV circular dichroism spectra of recombinant rgs-CaM in apo state (black), in the presence of $5 \mathrm{mM} \mathrm{CaCl}_{2}$ (red) and after subsequent addition of $5 \mathrm{mM}$ EGTA (blue). (For interpretation of the references to colour in this figure legend, the reader is referred to the web version of this article.)

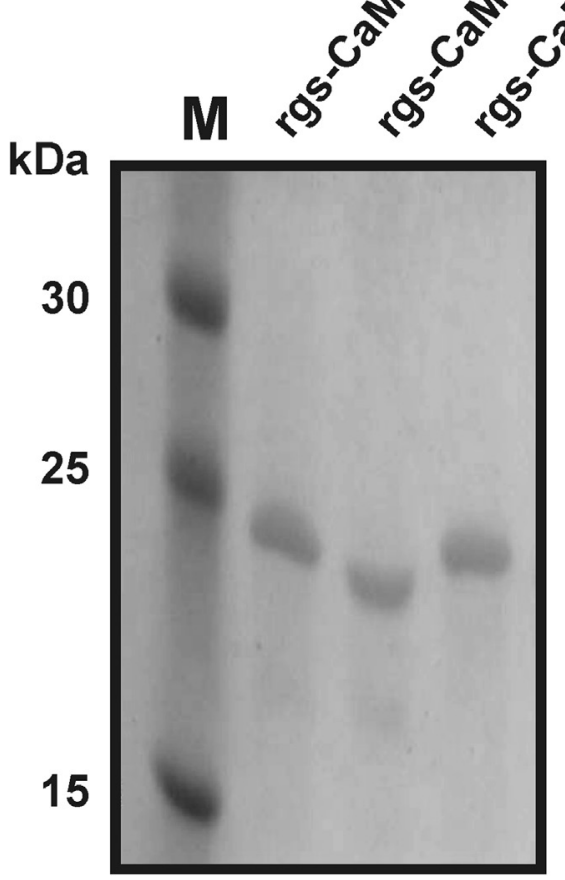

Fig. 3. Effects of $\mathrm{Ca}^{2+}$ on the electrophoretic mobility of recombinant rgs-CaM. The protein samples analyzed by $\mathrm{CD}$ (as described in the legend of Fig. 2) were subjected to PAGE (16\%) under semi-denaturing conditions. A faster migration of rgs-CaM in the presence of $\mathrm{CaCl}_{2}(5 \mathrm{mM})$ was observed. M: Molecular mass standard in kDa (PageRuler Plus Ladder $10-250 \mathrm{kDa}$; Fermentas). The gel was stained with Coomassie Brilliant Blue.

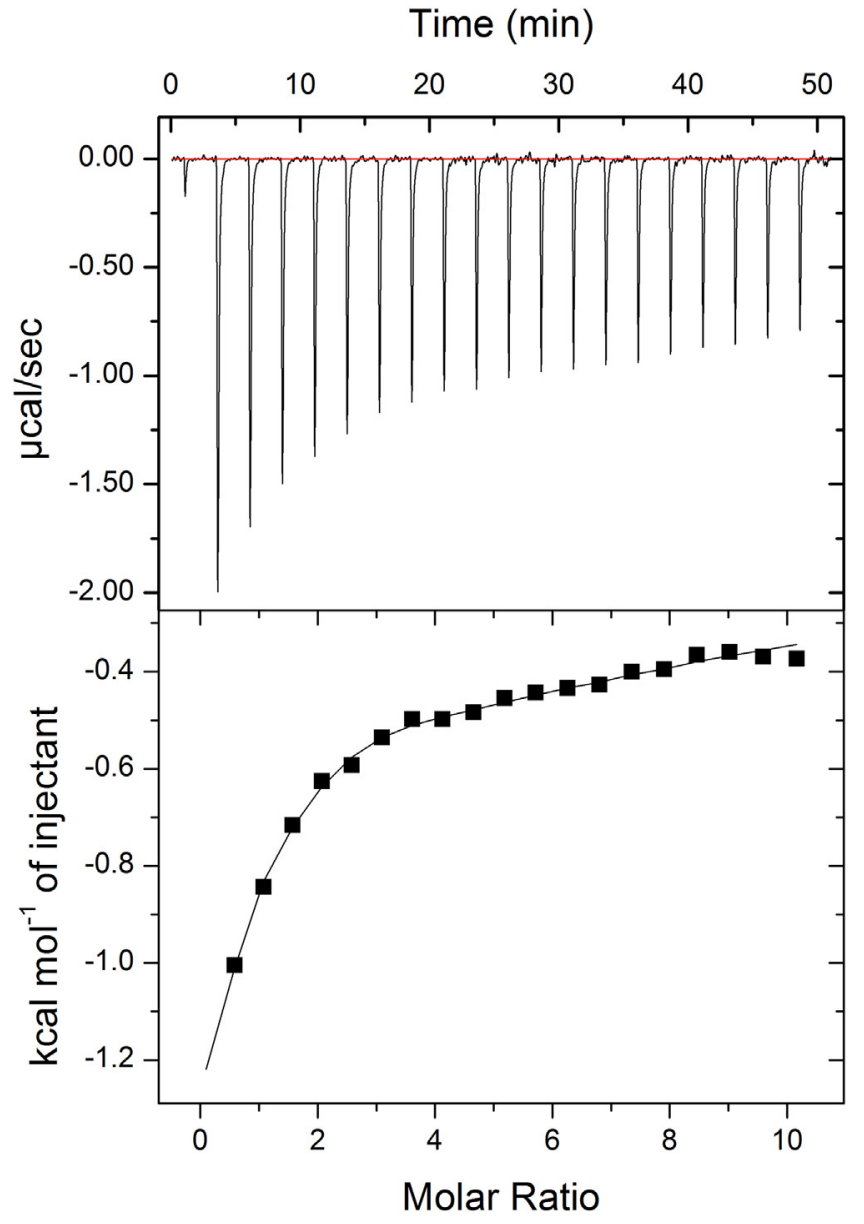

Fig. 4. Isothermal calorimetric data of $\mathrm{Ca}^{2+}$ binding to rgs-CaM. The top panel shows the raw power output ( $\mu \mathrm{cal} / \mathrm{s}$ ) per unit time (min). Bottom panel shows the integrated data $\left(\mathrm{kcal} / \mathrm{mol}\right.$ of injectant versus molar ratio of $\mathrm{Ca}^{2+}$ to rgs-CaM). These data were obtained from the raw power output as the area underneath each peak, which is then corrected for baseline heat injections and $\mathrm{Ca}^{2+}$ dilution heat and mixing. The solid line represents the best fit of the data to the sequential 3 binding site model.

Table 1

Thermodynamic parameters of $\mathrm{Ca}^{2+}$-binding to rgs-CaM obtained from ITC analysis.

\begin{tabular}{llll}
\hline Binding Site & $\mathrm{K}_{\mathrm{d}}(\mathrm{M})$ & $\Delta \mathrm{H}(\mathrm{kcal} / \mathrm{mol})$ & $\Delta \mathrm{S}(\mathrm{cal} / \mathrm{mol} / \mathrm{deg})$ \\
\hline 1 & $(1.27 \pm 0.07) \times 10^{-4}$ & $-2.10 \pm 0.07$ & 10.8 \\
2 & $(7.87 \pm 0.42) \times 10^{-5}$ & $0.32 \pm 0.09$ & 19.8 \\
3 & $(1.02 \pm 0.05) \times 10^{-2}$ & $-31.61 \pm 1.31$ & -96.9 \\
\hline
\end{tabular}

ico models confirmed that rgs-CaM, as classical CaMs, has $\mathrm{N}$ - and C-terminal globular lobes (with two putative $\mathrm{Ca}^{2+}$-binding loops each) separated by a central helix of 26 residues (Fig. 6). Moreover, all models showed an overall good quality, as evaluated by the distribution of residues in favored and allowed regions of the Ramachandran plot and by Z-score of ProSA-web [34] (Table 2). These models were deposited in the ModelArchive public database [35], and their Digital Object Identifier(DOI) are available in Table 2.

Interestingly, along the MD simulations of the rgs-CaM+Ca-A-B$\mathrm{C}-\mathrm{D}$ model, all $\mathrm{Ca}^{2+}$ ions remained coordinated in their loops, with the exception of the one present in loop C (Fig. 6A). The same feature was observed when $\mathrm{Ca}^{2+}$ was loaded only on loop $\mathrm{C}$ (rgs-CaM+Ca-C model), suggesting that this loop is unable to coordinate $\mathrm{Ca}^{2+}$. These results are consistent with the aforementioned sequence alignment predictions and ITC data, thus indicating that rgs-CaM, unlike classical CaMs, has only three sites of $\mathrm{Ca}^{2+}$ coordination, namely loops A, B and D. 
Table 2

Overall quality, radius of gyration ( $\mathrm{Rg}$ ) and Digital Object Identifiers of rgs-CaM in silico models deposited on ModelArchive public database.

\begin{tabular}{|c|c|c|c|c|}
\hline Model & Z-score ${ }^{a}$ & Residues in allowed and favored regions (\%) & $\operatorname{Rg}(\mathrm{nm})^{c}$ & $\mathrm{DOI}^{\mathrm{d}}$ \\
\hline apo-rgs-CaM & -7.4 & 100 & 1.7 & ma-asrjx \\
\hline rgs-CaM+Ca-A-B-C-D & -5.6 & 98.6 & 2.3 & ma-a9cbt \\
\hline rgs-CaM+Ca-A-B-D & -5.4 & 96.4 & 2.3 & ma-awfwa \\
\hline rgs-CaM+Ca-A-D & -6.1 & 98.9 & 2.2 & ma-a2nix \\
\hline rgs-CaM+Ca-C & -4.7 & 99.3 & 1.8 & ma-aborg \\
\hline
\end{tabular}

a Calculated by ProSa-web [27].

b According to Ramachandra plot calculated by RAMPAGE [17].

c Calculated by GROMACS v.4.5.3 [15].

d Digital object identifier (DOI) of the in silico structure deposited on ModelArchive [33] public database.

A
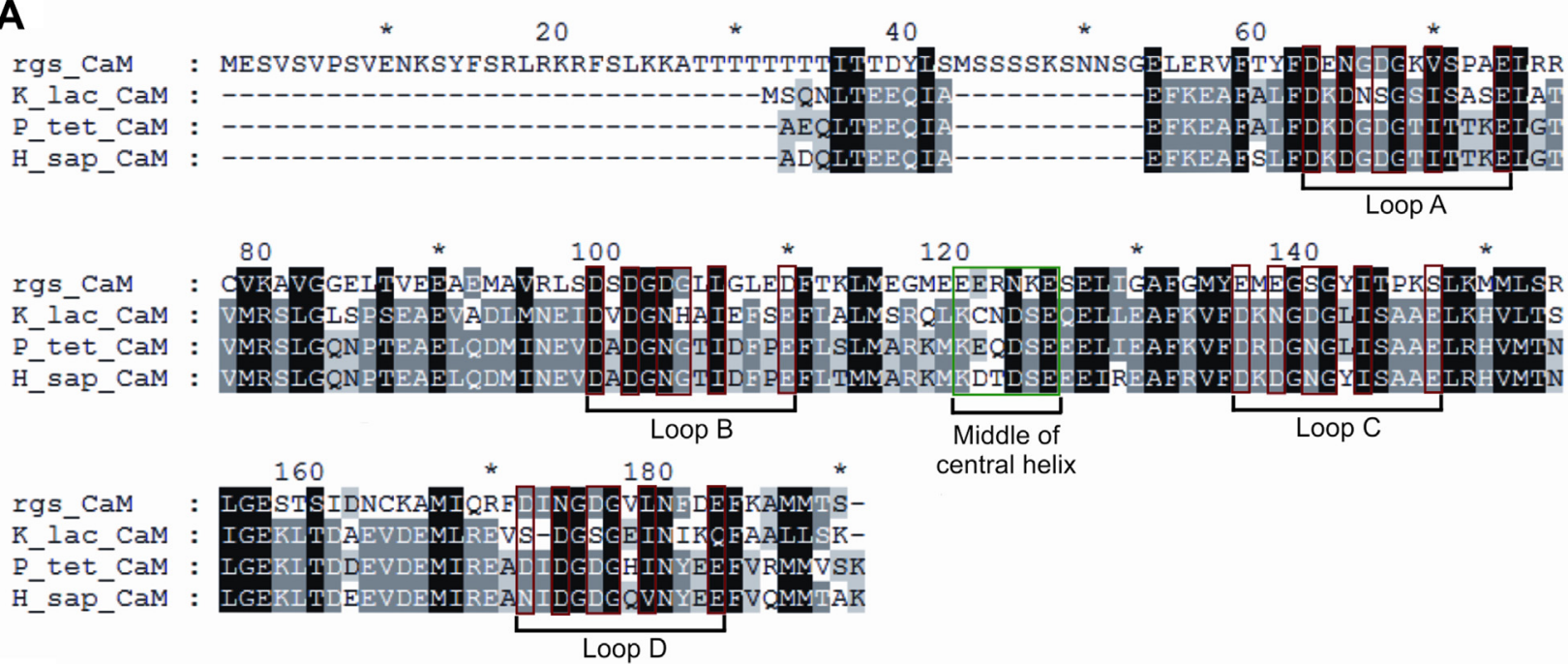

central helix

B
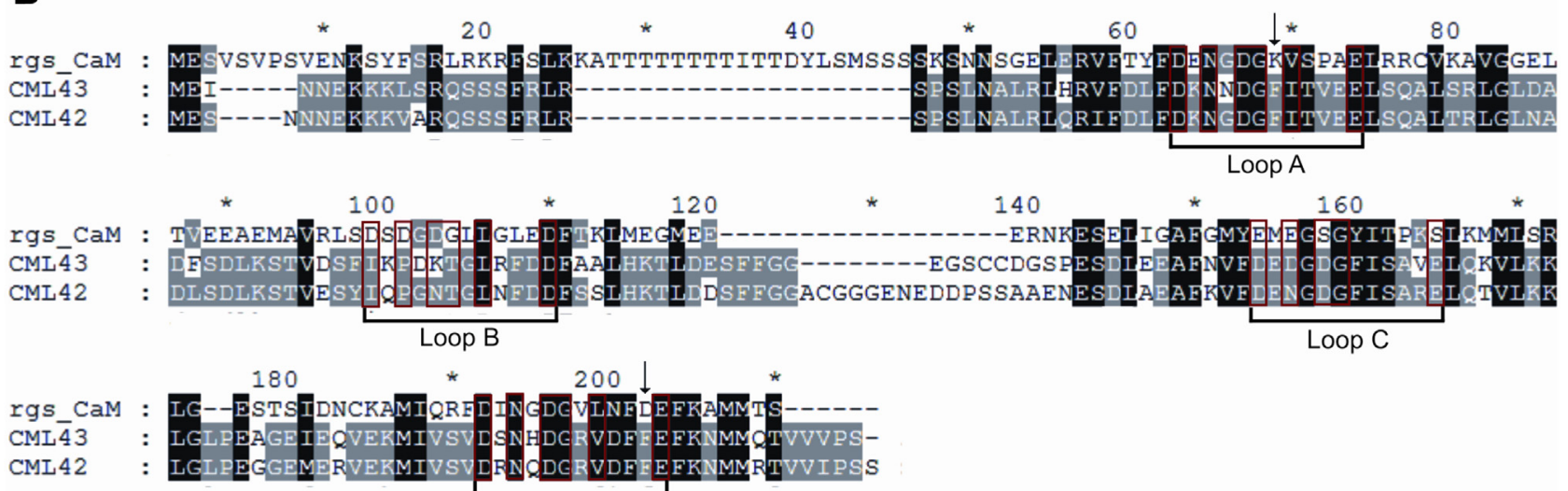

Loop D

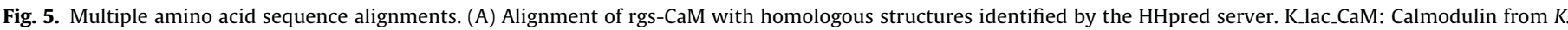

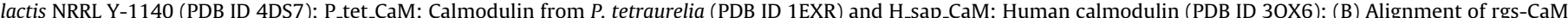

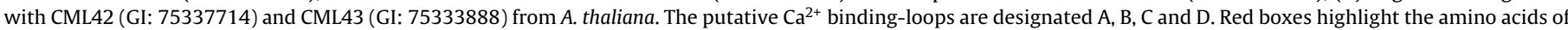

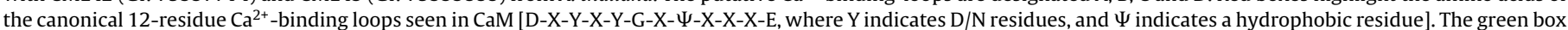

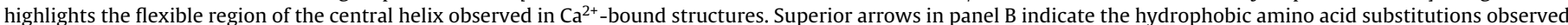

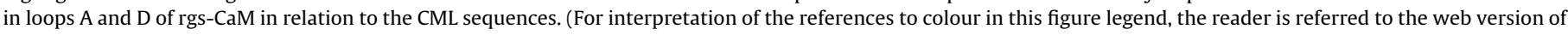
this article.)

3.6. In silico models of $\mathrm{Ca}^{2+}$-bound rgs-CaM detected an expansion on its tertiary structure with exposition of a large negatively charged surface

It has been previously reported that $\mathrm{Ca}^{2+}$-bound CaMs have a more expanded tertiary structure than their apo counterparts $[13,36]$. In this regard, we found that the removal of all $\mathrm{Ca}^{2+}$ resulted in a more compact rgs-CaM model compared to the one loaded with three $\mathrm{Ca}^{2+}$. This observation was well correlated with the $\mathrm{Rg}$ values of both apo and four calcium-containing rgs-CaM models $\left(1.7 \mathrm{~nm}\right.$ versus $2.3 \mathrm{~nm}$; Table 2 ). Thus, the loading of $\mathrm{Ca}^{2+}$ into loops A, B and D promoted an expansion of the tertiary structure of rgs-CaM, as already reported for CaMs [37]. C $\alpha$ superposition of the central helix of the rgs-CaM+Ca-A-B-C model over the central helix of the apo-rgs-CaM model clearly illustrates this expansion. In this case, a different reorientation of the EF-hand helices 
A

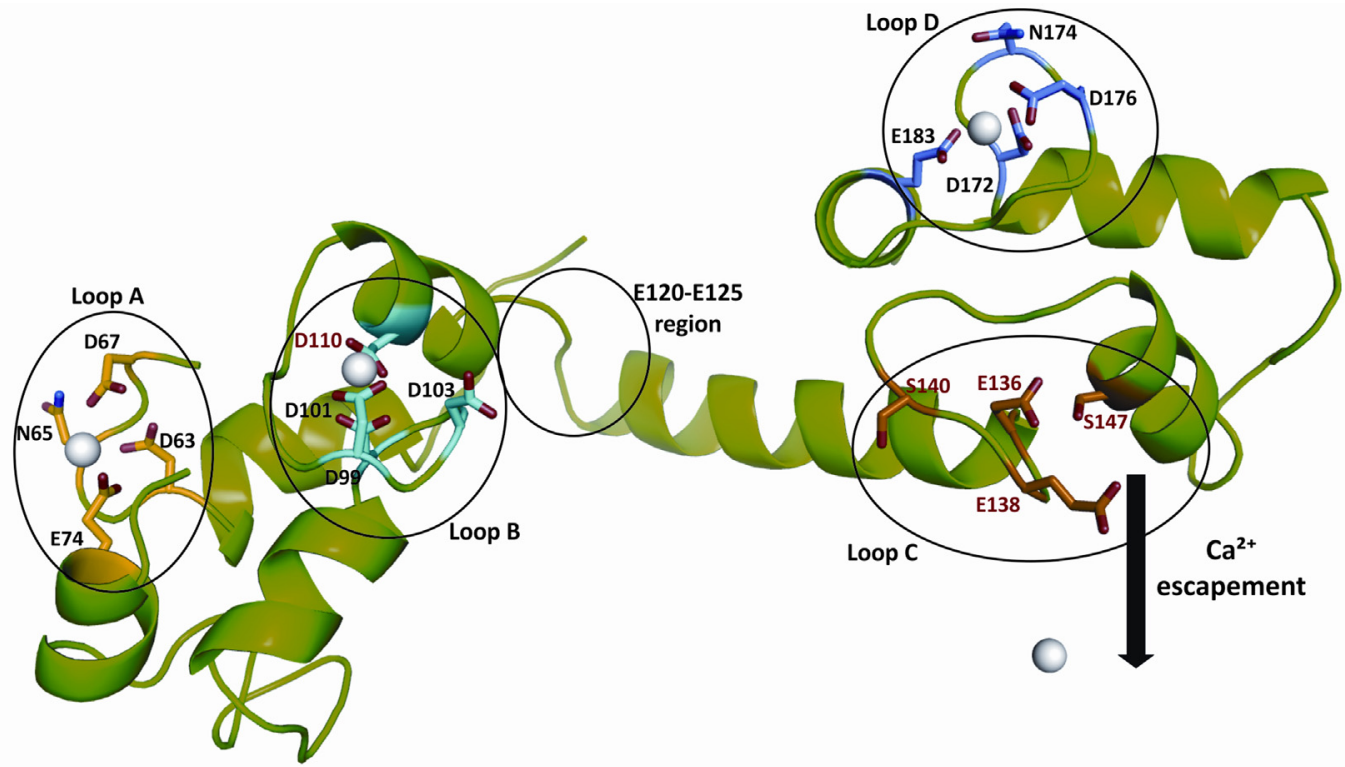

B
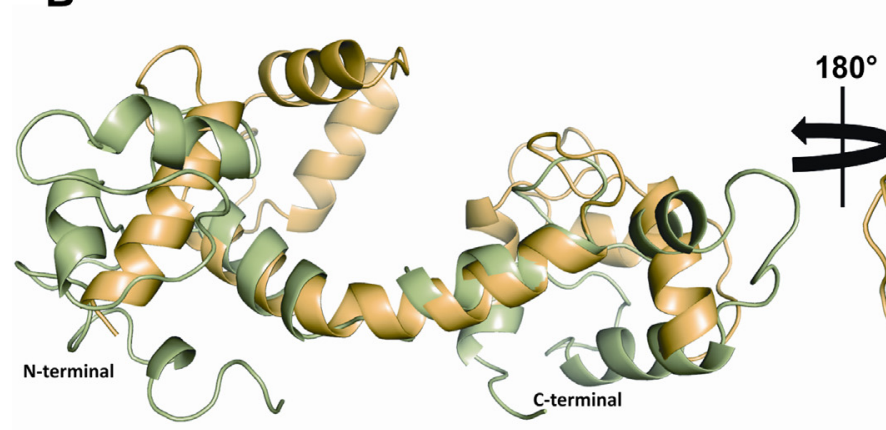

apo-rgs-CaM

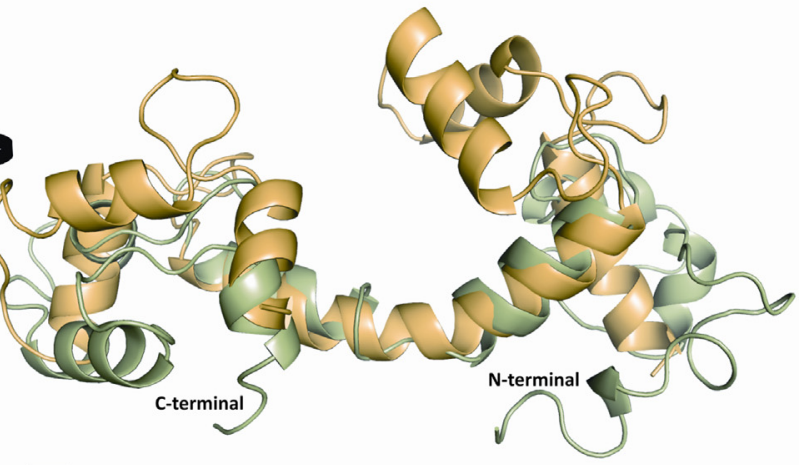

rgs-CaM+Ca-A-B-D

Fig. 6. In silico modeling of rgs-CaM. (A) Cartoon representation of the final rgs-CaM model with $\mathrm{Ca}^{2+}$ modeled in the four predicted $\mathrm{Ca}^{2+}$-binding loops $(\mathrm{rgs}-\mathrm{CaM}+\mathrm{Ca}-\mathrm{A}-\mathrm{B}-\mathrm{C}-\mathrm{D}$ model). The residues predicted to coordinate $\mathrm{Ca}^{2+}$ in rgs-CaM are represented by sticks. Along the MD simulations, the $\mathrm{Ca}^{2+}$ in loop $\mathrm{C}$ escaped from the loop whereas the other ions remained coordinated in the other loops. The flexible region near the middle of the central helix (E120-E125) is also highlighted. (B) Cartoon representation of $\mathrm{C} \alpha$ superposition of the central helix of rgs-CaM+Ca-A-B-D (green) over apo-rgs-CaM (yellow) showing the expansion of rgs-CaM tertiary structure and the different reorientations of the helices within the EF-hands upon $\mathrm{Ca}^{2+}$ binding. (For interpretation of the references to colour in this figure legend, the reader is referred to the web version of this article.)
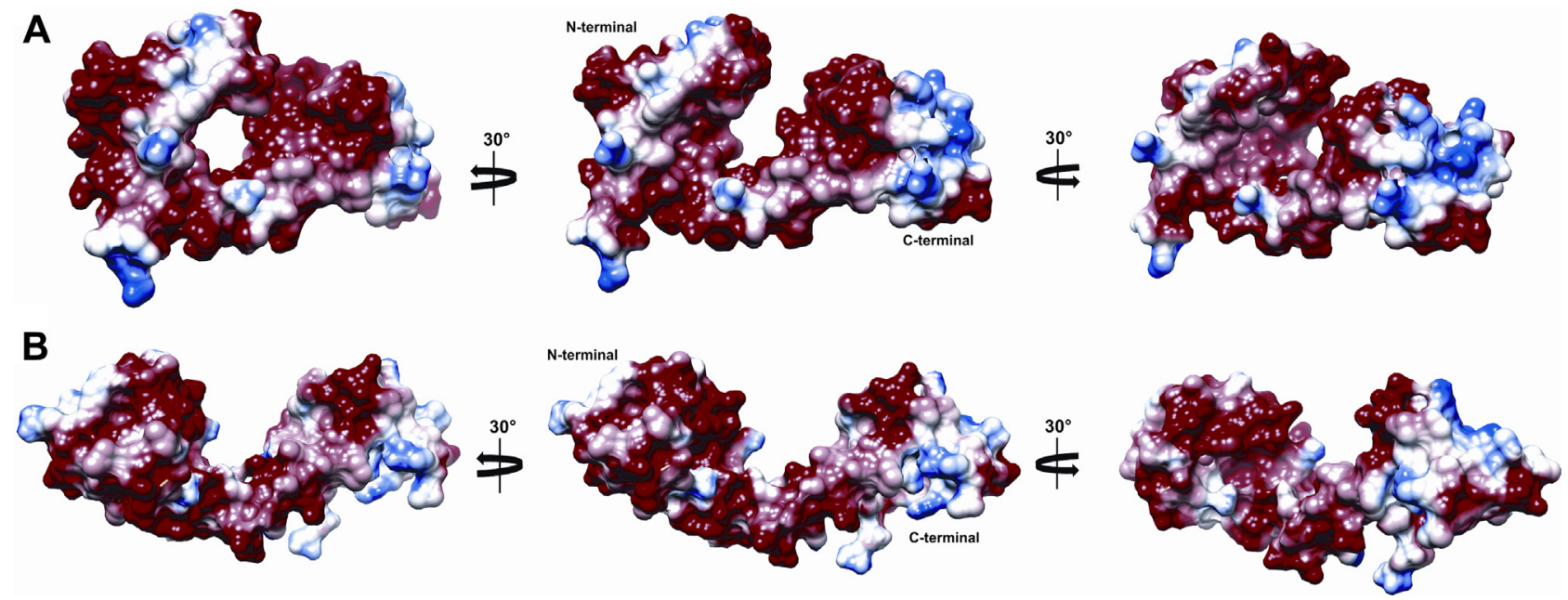

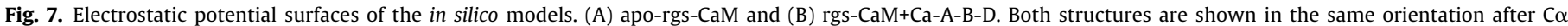

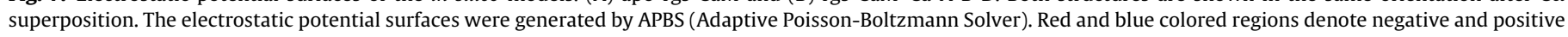
charges, respectively. (For interpretation of the references to colour in this figure legend, the reader is referred to the web version of this article.) 

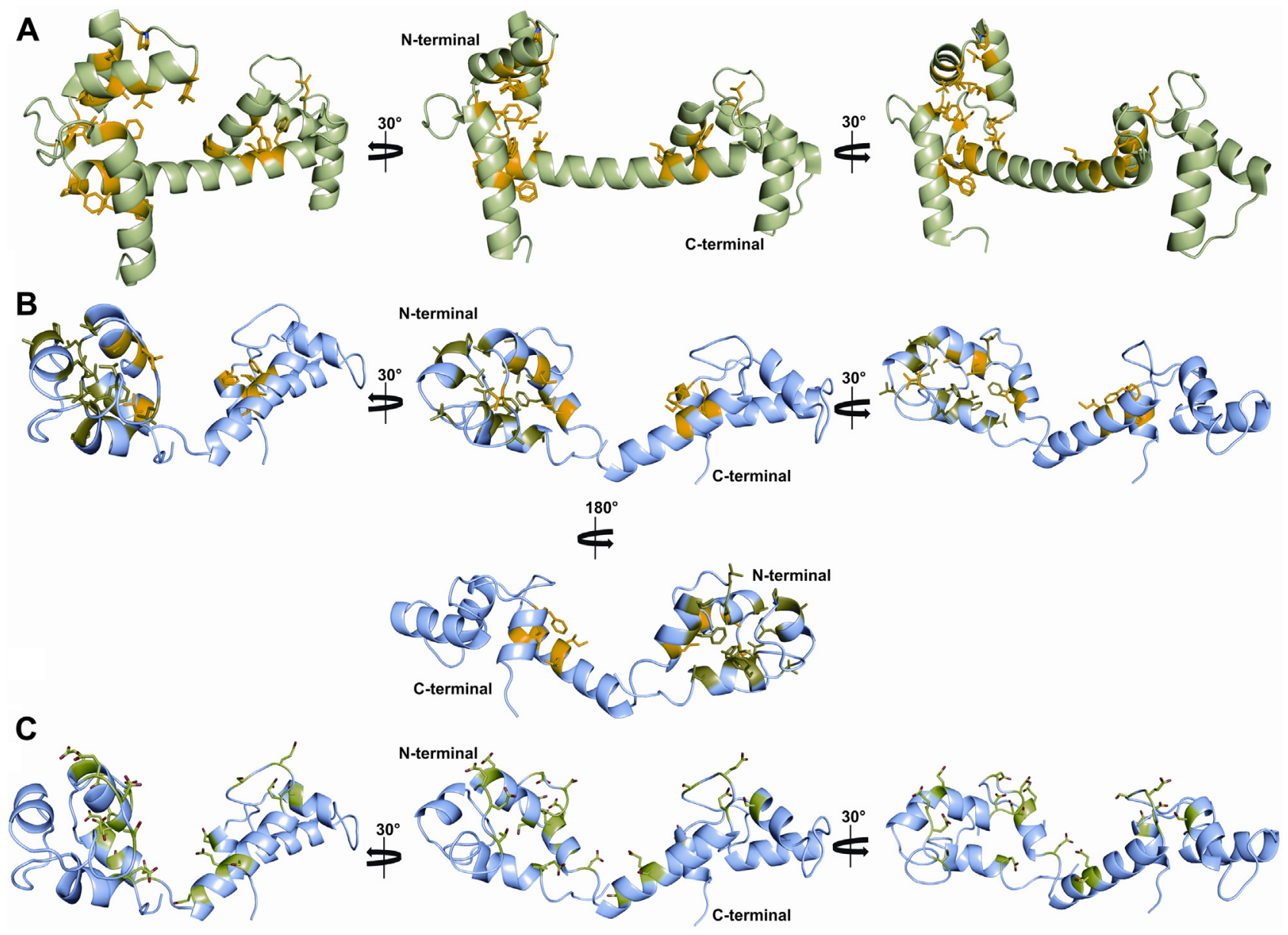

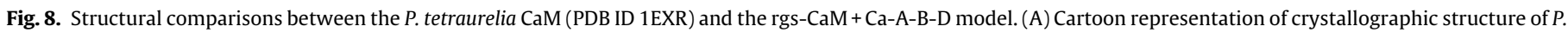

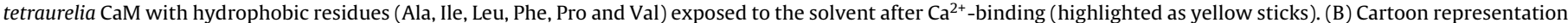

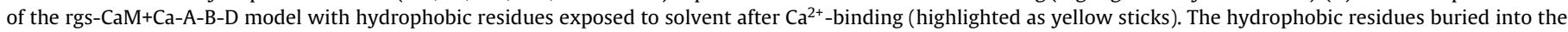

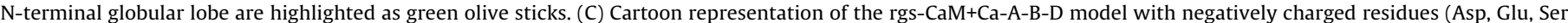

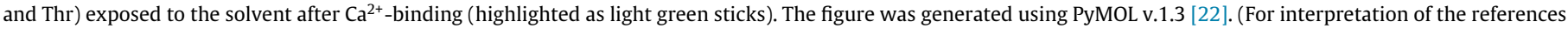
to colour in this figure legend, the reader is referred to the web version of this article.)

between apo- and calcium-containing models could be observed (Fig. 6B). Interestingly, when $\mathrm{Ca}^{2+}$ was loaded into loops $\mathrm{A}$ and $\mathrm{D}$ but not B (rgs-CaM-A-D model), rgs-CaM adopted an expanded tertiary structure conformation showing an $\mathrm{Rg}$ value around $2.3 \mathrm{~nm}$ (Table 2).

Along the MD simulations of the rgs-CaM models with $\mathrm{Ca}^{2+}$ loaded into, at least, loops $\mathrm{A}$ and $\mathrm{D}$ (rgs-CaM+Ca-A-B-D and rgs$\mathrm{CaM}+\mathrm{Ca}-\mathrm{A}-\mathrm{D}$ models), a region near the middle of the central helix (E120 through E125 as denoted in Fig. 5A) presented great mobility, adopting even a disordered secondary structure at the end of the majority of the simulations (Fig. 6A). This flexibility confers to the central helix a bendable joint on its center that probably contributes to the reorientation of the EF-hands to become more solvent-exposed in the $\mathrm{Ca}^{2+}$-bound models (Fig. 6B). In contrast, in MD simulations of apo-rgs-CaM, this region remained stable during all $100 \mathrm{~ns}$ simulations. The deduced amino acid sequence alignments revealed that the E120-E125 region of rgs-CaM is analogous to the K77-S81 region of classical CaMs (Fig. 5A), which is also located in the middle of the central helix and has a high degree of mobility as previously shown by NMR assays [37].

Another typical feature of classical CaM is the exposure of a significant amount of non-polar surface area upon expansion of its tertiary structure $[37,38]$. This solvent-exposed area results in a hydrophobic pocket that serves as a target interaction site [32]. In this context, Nakahara et al. [4] reported previously that rgs-
CaM can interact with the $2 \mathrm{~b}$ suppressor of Tomato aspermy virus by electrostatic interactions, thus contrasting with classical CaMs that usually use hydrophobic patches to interact with their targets $[6,7]$. In fact, a comparative analysis of the electrostatic potential surfaces of the apo-rgs-CaM and rgs-CaM+Ca-A-B-D models in the same orientation revealed that the $\mathrm{Ca}^{2+}$-induced conformational expansion leads to the exposure of a negatively charged region (Fig. 7). This anionic area is located mainly on the N-terminal globular lobe and is complemented by some portions of the central helix and C-terminal lobe, thus forming a large and negatively charged pocket. A careful comparison between the crystallographic structure of the $\mathrm{Ca}^{2+}$-bound CaM from $P$. tetraurelia (PDB ID: 1EXR) and the rgs-CaM+Ca-A-B-D model reveals a different distribution of the conserved hydrophobic residues on these structures (Fig. 8). In the CaM from P. tetraurelia, the surface-exposed hydrophobic residues are located mainly on the $\mathrm{N}$-terminal globular lobe and in some portions of the central helix and C-terminal lobe (Fig. 8A). In contrast, the corresponding regions of the rgs-CaM+Ca-A-B-D model have fewer solvent-exposed hydrophobic residues and contain several negatively charged residues (Fig. 8C). This is especially true for the $\mathrm{N}$-terminal lobe in which the majority of the residues are buried into the EF-hand structure (Fig. 8B). These negative residues comprise the anionic pocket that could be responsible for the interaction of rgs-CaM with the dsRNA-binding domains of viral suppressors. 


\section{Discussion}

Rgs-CaM is a CaM-related protein involved in the dynamic interplay between viruses and plants. Conflicting results from different groups suggest that rgs-CaM could target viral suppressors for autophagic degradation [4] or interact with them having a positive effect on suppressor activity [3]. Earlier homology modeling studies demonstrated that rgs-CaM possesses two predicted EFhand motifs separated by a negatively charged cleft [4]. Despite the presence of these predicted EF-hands, the ability of rgs-CaM to bind $\mathrm{Ca}^{2+}$ and its effective role as a $\mathrm{Ca}^{2+}$ sensor remain elusive.

In this regard, our $\mathrm{CD}$ spectral data revealed that rgs-CaM is sensitive to $\mathrm{Ca}^{2+}$ binding, but only modest effects on its overall secondary structure are detected upon binding (Fig. 2). Our results using EGTA in CD measurements and mobility shift assays showed that $\mathrm{Ca}^{2+}$ binding to rgs-CaM is a reversible process. Moreover, by generating structural in silico models for calcium-free and calciumbound rgs-CaM (Fig. 6B; Table 2), we found that rgs-CaM structure undergoes a calcium-induced expansion and reorientation of the alpha-helices within the EF-hands (Fig. 6B; Table 2). This conformational change is commonly observed in classical CaMs [37]. The reorientation of the helices leads to exposure to the solvent of a large EF-hand area that could be responsible for the slight increase in molar ellipticity at $222 \mathrm{~nm}$ detected upon $\mathrm{Ca}^{2+}$ addition to rgsCaM (Fig. 2), as previously observed for CML43 [28]. Additionally, in our $\mathrm{Ca}^{2+}$-bound rgs-CaM models, a higher flexibility near the middle of the central helix along the MD simulations was noted, a feature that probably contributes to the EF-hand rearrangements.

Our ITC data indicate that rgs-CaM has only three functional $\mathrm{Ca}^{2+}$-binding sites. This was further supported by the information gleaned from amino acid sequence predictions and by inspection of the rgs-CaM models generated in silico. Collectively, our results indicate that loop $\mathrm{C}$ in the C-terminal EF-hand of rgs-CaM is unable to bind calcium. Remarkably, this loop shows no conservation of the residues typically found in canonical $\mathrm{Ca}^{2+}$-binding loops of classical CaMs (Fig. 5A). Bender et al. [28] reported that A. thaliana CML43, which acts as a $\mathrm{Ca}^{2+}$ sensor, also possesses only three functional $\mathrm{Ca}^{2+}$-binding loops. One of them has high $\mathrm{Ca}^{2+}$ affinity [dissociation constants $\left(\mathrm{k}_{d}\right)$ of $8.16 \mathrm{nM}$ ] and is supposed to play a structural role, whereas the two remaining loops have moderate $\mathrm{Ca}^{2+}$ affinity $\left(\mathrm{k}_{d}=4.85 \mu \mathrm{M}\right)$ and are supposed to be regulatory. In contrast to rgs-CaM, the non-functional loop of CML43 (loop B) is located in the N-terminal EF-hand and shows no conservation of the residues involved in $\mathrm{Ca}^{2+}$ coordination (Fig. 5B).

According to the ITC results, rgs-CaM has two $\mathrm{Ca}^{2+}$-binding sites (sites $\mathrm{A}$ and $\mathrm{D}$ ) with moderate $\mathrm{Ca}^{2+}$ affinity $\left(\mathrm{k}_{d}=78.7 \mu \mathrm{M}\right.$ and $127 \mu \mathrm{M}$, sites 1 and 2 in Table 1 ), and a third one (B) with low $\mathrm{Ca}^{2+}$ affinity $\left(\mathrm{k}_{d}=10.2 \mathrm{mM}\right.$; site 3 in Table 1$)$. This moderate/low $\mathrm{Ca}^{2+}$ affinity may be attributed to the substitution of conserved hydrophobic residues within the EF-hands, especially in loops A and D (Fig. 5B). Surprisingly, despite the fact that rgs-CaM possesses several features of $\mathrm{Ca}^{2+}$ sensor, as indicated by our structural data, the $\mathrm{k}_{d}$ values determined by ITC are not within the affinity range of a typical $\mathrm{Ca}^{2+}$ sensor (1-0.1 $\left.\mu \mathrm{M}\right)$ [12]. This fact, however, does not preclude the role of rgs-CaM as a sensor since its $\mathrm{Ca}^{2+}$ affinity may be increased in the presence of its target viral suppressor. This phenomenon has already been reported for other known CaMs [12]. In mammals, for example, the affinity of CaM for $\mathrm{Ca}^{2+}$ was increased 25 -fold in the presence of its interacting protein [38]. Interestingly, basal cytosolic levels of $\mathrm{Ca}^{2+}$ (about $100 \mathrm{nM}$ ) [12,39] were insufficient to induce important structural changes in rgs-CaM. It seems therefore likely that the observed expansion in rgs-CaM structure could be triggered by transitory increases in cytosolic $\mathrm{Ca}^{2+}$ levels as would be expected during pathogen attack. Consistent with this, previous studies have shown that rgs-CaM is widely expressed immediately after wounding [5], a stress that occurs simultane- ously to virus invasion and is also reported to alter $\mathrm{Ca}^{2+}$ homeostasis [40].

Of note, the thermodynamic results relative to sites $A$ and $D$ (sites 1 and 2 in Table 1 ), revealing small enthalpy and large positive entropy changes, corroborate the observed $\mathrm{Ca}^{2+}$-dependent conformational modification [12]. Concerning site B (site 3 in Table 1), despite its low $\mathrm{Ca}^{2+}$ affinity, this site showed a large and exothermic enthalpy and an unfavorable binding entropy in calorimetric studies. This is consistent with the large and exothermic enthalpy observed for $\mathrm{Ca}^{2+}$-binding of calbindin $\mathrm{D}_{9 \mathrm{k}}$ due to the dehydration of the EF-hands [11]. Most noteworthy is the fact that the absence of $\mathrm{Ca}^{2+}$ in site $\mathrm{B}$ has no impact on the expansion of the rgs-CaM tertiary structure. Accordingly, rgs-CaM adopted the same expanded conformation when $\mathrm{Ca}^{2+}$ was loaded into sites $\mathrm{A}$ and $\mathrm{D}$ or into the three predicted $\mathrm{Ca}^{2+}$-binding sites.

Despite corroborating previous findings suggesting that rgsCaM interacts with its targets by electrostatic interactions [4], our results provide additional information about peculiar aspects of this protein. Most importantly, we observed that the binding of two $\mathrm{Ca}^{2+}$ to rgs-CaM is sufficient to promote surface exposure of a large negatively charged pocket, which might be responsible for its interaction with the dsRNA-binding domains of viral suppressors.

\section{Conclusions}

The results obtained indicate that rgs-CaM has three putative $\mathrm{Ca}^{2+}$-binding sites. However, $\mathrm{Ca}^{2+}$ binding to the two sites possessing higher $\mathrm{Ca}^{2+}$ affinity is sufficient to trigger a conformational change in an expanded structure with reorientation of the helices within the EF-hands. In addition, our structural data support the idea that rgs-CaM interacts with its targets through electrostatic interactions, thus contrasting classical CaMs that usually use hydrophobic patches $[6,7]$. It seems plausible that these negatively charged residues comprised within an anionic pocket might be responsible for the interaction of rgs-CaM with the dsRNA-binding domains of viral suppressors.

\section{Author contributions}

Conceived and designed the work: RKM, CAHF, MRMF and IGM. Performed the experiments: RKM, CAHF, TRD, BSM and FFM. Wrote the manuscript: MRMF and IGM with feedback from CAHF.

\section{Acknowledgments}

R. K. Makiyama was recipient of a PhD fellowship from FAPESP (2010/03001-0). C. A. H. Fernandes is recipient of a post-doctoral fellowship from FAPESP (2013/17864-8). I. G. Maia and M. R. M. Fontes are recipients of research fellowships from CNPq. Computational resources were supplied by the Center for Scientific Computing (NCC/GridUNESP) of the São Paulo State University (UNESP).

\section{Appendix A. Supplementary data}

Supplementary data associated with this article can be found, in the online version, at http://dx.doi.org/10.1016/j.ijbiomac.2016. 08.016 .

\section{References}

[1] S.W. Ding, O. Voinnet, Antiviral immunity directed by small RNA, Cell 130 (2007) 413-426.

[2] R. Anandalakshmi, R. Marathe, X. Ge, J.M. Herr, C. Mau, A. Mallory, G. Pruss, L. Bowman, V.B. Vance, A calmodulin-related protein that suppresses posttranscriptional gene silencing in plants, Science 290 (2000) 142-144. 
[3] F. Li, C. Huang, Z. Li, X. Zhou, Suppression of RNA silencing by a plant DNA virus satellite requires a host calmodulin-like protein to repress RDR6 expression, PLoS Pathog. 10 (2014) e1003921.

[4] K.S. Nakahara, C. Masuta, S. Yamada, H. Shimura, Y. Kashihara, T.S. Wada, A. Meguro, K. Goto, K. Tadamura, K. Sueda, T. Sekiguchi, J. Shao, N. Itchoda, T. Matsumura, M. Igarashi, K. Ito, R.W. Carthew, I. Uyeda, Tobacco calmodulin-like protein provides secondary defense by binding to and directing degradation of virus RNA silencing suppressors, Proc. Natl. Acad. Sci. U. S. A. 109 (2012) 10113-10118.

[5] K. Tadamura, K.S. Nakahara, C. Masuta, I. Uyeda, Wound-induced rgs-CaM gets ready for counterresponse to an early stage of viral infection, Plant Signal. Behav. 7 (2012) 1548-1551.

[6] W.A. Snedden, H. Fromm, Calmodulin, calmodulin-related proteins and plant responses to the environment, Trends Plant Sci. 3 (1998) 299-304.

[7] C. Yang, G.S. Jas, K. Kuczera, Structure, dynamics and interaction with kinase targets: computer simulations of calmodulin, Biochim. Biophys. Acta 1697 (2004) 289-300.

[8] J.M. Khan, A Oadeer, S.K. Chaturvedi, E. Ahmad, S.A. Rehman, S. Gourinath, R.H. Khan, SDS can be utilized as an amyloid inducer: a case study on diverse proteins, PLoS One 7 (2012) e29694.

[9] J.M. Khan, S.A. Abdulrehman, F.K. Zaidi, S. Gourinath, R.H. Khan, Hydrophobicity alone can not trigger aggregation in protonated mammalian serum albumins, Phys. Chem. Chem. Phys. 16 (2014) 5150-5161.

[10] J.M. Khan, S.K. Chaturvedi, S.K. Rahman, M. Ishtikhar, A. Qadeer, E. Ahmad, R.H. Khan, Protonation favors aggregation of lysozyme with SDS, Soft Matter 10 (2014) 2591-2599.

[11] D. Dell'Orco, W.F. Xue, E. Thulin, S. Linse, Electrostatic contributions to the kinetics and thermodynamics of protein assembly, Biophys. J. 88 (2005) 1991-2002.

[12] J.L. Gifford, M.P. Walsh, H.J. Vogel, Structures and metal-ion-binding properties of the $\mathrm{Ca}^{2+}$-binding helix-loop-helix EF-hand motifs, Biochem. J. 405 (2007) 199-221.

[13] M.A. Wilson, A.T. Brunger, The 1.0 A crystal structure of $\mathrm{Ca}^{(2+)}$-bound calmodulin: an analysis of disorder and implications for functionally relevant plasticity, J. Mol. Biol. 301 (2000) 1237-1256.

[14] Z. Grabarek, Structural basis for diversity of the EF-hand calcium-binding proteins, J. Mol. Biol. 359 (2006) 509-525.

[15] C. Michaux, N.C. Pomroy, G.G. Privé, Refolding SDS-denatured proteins by the addition of amphipathic cosolvents, J. Mol. Biol. 375 (2008) 1477-1488.

[16] C. Michaux, J. Pouyez, J. Wouters, G.G. Privé, Protecting role of cosolvents in protein denaturation by SDS: a structural study, BMC Struct. Biol. 8 (2008) 29.

[17] E. Gasteiger, C. Hoogland, A. Gattiker, S. Duvaud, M.R. Wilkins, R.D. Appel, A. Bairoch, Protein identification and analysis tools on the ExPASy Server, in: J.M. Walker (Ed.), The Proteomics Protocols Handbook, Humana Press, 2005, pp. 571-607.

[18] D. Chiasson, S.K. Ekengren, G.B. Martin, S.L. Dobney, W.A. Snedden, Calmodulin-like proteins from Arabidopsis and tomato are involved in host defense against Pseudomonas syringae pv. tomato, Plant Mol. Biol. 58 (2005) 887-897.

[19] J. Söding, A. Biegert, A.N. Lupas, The HHpred interactive server for protein homology detection and structure prediction, Nucleic Acids Res. 33 (2005) 244-248.

[20] M.A. Martin-Renom, A.C. Stuart, A. Fiser, R. Sánchez, F. Melo, A. Sali, Comparative protein structure modelling of genes and genomes, Annu. Rev Biophys. Biomol. Struct. 29 (2000) 291-325.

[21] D. Van Der Spoel, E. Lindahl, B. Hess, G. Groenhof, A.E. Mark, H.J. Berendsen, GROMACS: fast, flexible, and free, J. Comput. Chem. 26 (2005) 1701-1718.
[22] M. Christen, P.H. Hünenberger, D. Bakowies, R. Baron, R. Bürgi, D.P. Geerke, T.N. Heinz, M.A. Kastenholz, V. Kräutler, C. Oostenbrink, C. Peter, D. Trzesniak, W.F. van Gunsteren, The GROMOS software for biomolecular simulation: GROMOS05, J. Comput. Chem. 26 (2005) 1719-1751.

[23] S.C. Lovell, I.W. Davis, W.B. Arendall 3rd, P.I. de Bakker, J.M. Word, M.G. Prisant, J.S. Richardson, D.C. Richardson, Structure validation by Calpha geometry: phi, psi and Cbeta deviation, Proteins 50 (2003) 437-450.

[24] E.F. Pettersen, T.D. Goddard, C.C. Huang, G.S. Couch, D.M. Greenblatt, E.C. Meng, T.E. Ferrin, UCSF Chimera - a visualization system for exploratory research and analysis, J. Comput. Chem. 25 (2004) 1605-1612.

[25] T.J. Dolinsky, J.E. Nielsen, J.A. McCammon, N.A. Baker, PDB2PQR: an automated pipeline for the setup of Poisson-Boltzmann electrostatics calculations, Nucleic Acids Res. 32 (2004) W665-W667.

[26] W.S. Delano, The PyMOL molecular graphics system. Palo Alto, DeLano Scientific (2002)

[27] S. Dash, W. Niemaczura, H.M. Harrington, Characterization of the basic amphiphilic $\alpha$-helix calmodulin-binding domain of a $61.5 \mathrm{kDa}$ tobacco calmodulin-binding protein, Biochemistry 36 (1997) 2025-2029.

[28] K.W. Bender, S. Dobney, A. Ogunrinde, D. Chiasson, R.T. Mullen, H.J. Teresinski, P. Singh, K. Munro, S.P. Smith, W.A. Snedden, The calmodulin-like protein CML43 functions as a salicylic-acid-inducible root-specific $\mathrm{Ca}^{2+}$ sensor in Arabidopsis, Biochem. J. 457 (2014) 127-136.

[29] S. Dobney, D. Chiasson, P. Lam, S.P. Smith, W.A. Snedden, The calmodulin-related calcium sensor CML42 plays a role in trichome branching, J. Biol. Chem. 284 (2009) 31647-31657.

[30] M. Garrigos, S. Deschamps, A. Viel, S. Lund, P. Champeil, J.V. Moller, M. le Maire, Detection of $\mathrm{Ca}^{2+}$-binding proteins by electrophoretic migration in the presence of $\mathrm{Ca}^{2+}$ combined with $45 \mathrm{Ca}^{2+}$ overlay of protein blots, Anal. Biochem. 194 (1991) 82-88.

[31] B. Vanderbeld, W.A. Snedden, Developmental and stimulus-induced expression patterns of Arabidopsis calmodulin-like genes CML37, CML38 and CML39, Plant Mol. Biol. 64 (2007) 683-697.

[32] R. Gilli, D. Lafitte, C. Lopez, M.-C. Kilhoffer, A. Makarov, C. Briand, J. Haiech, Thermodynamic analysis of calcium and magnesium binding to calmodulin, Biochemistry 37 (1998) 5450-5456.

[33] G. Wu, Z. Gao, A. Dong, S. Yu, Calcium-induced changes in calmodulin structural dynamics and thermodynamics, Int. J. Biol. Macromol. 50 (2012) 1011-1017.

[34] M. Wiederstein, M.J. Sippl, Prosa-web: interactive web service for the recognition of errors in three-dimensional structures of proteins, Nucleic Acids Res. 35 (2007) W407-W410.

[35] J. Haas, S. Roth, K. Arnold, F. Kiefer, T. Schmidt, L. Bordoli, T. Schwede, The Protein Model Portal - a comprehensive resource for protein structure and model information, Database 2013 (2013), bat031.

[36] M. Zhang, T. Tanaka, M. Ikura, Calcium induced conformational transition revealed by the solution structure of apo calmodulin, Nat. Struct. Biol. 2 (1995) 758-767

[37] G. Barbato, M. Ikura, L.E. Kay, R.W. Pastor, A. Bax, Backbone dynamics of calmodulin studied by $\mathrm{N}-15$ relaxation using inverse detected 2-dimensional NMR-spectroscopy - The central helix is flexible, Biochemistry 31 (1992) 5269-5278.

[38] B.B. Olwin, D.R. Storm, Calcium binding to complexes of calmodulin and calmodulin binding proteins, Biochemistry 24 (1985) 8081-8086.

[39] S.J. Swanson, W.-G. Choi, A. Chanoca, S. Gilroy, In vivo imaging of $\mathrm{Ca}^{2+}$, $\mathrm{pH}$ and reactive oxygen species using fluorescent probes in plants, Annu. Rev Plant Biol. 62 (2011) 273-297.

[40] T. Suntio, K. Mäkinen, Abiotic stress responses promote Potato virus A infection in Nicotiana benthamiana, Mol. Plant Pathol. 13 (2012) 775-784. 